\title{
A Putatively New Family of Alphaproteobacterial Chloromethane Degraders from a Deciduous Forest Soil Revealed by Stable Isotope Probing and Metagenomics
}

\section{Eileen Kröber}

Max Planck Institute for Aeronomy: Max-Planck-Institut fur Sonnensystemforschung

\section{Saranya Kanukollu}

Leibniz-Zentrum fur Agrarlandschaftsforschung e V Bibliothek

\section{Sonja Wende}

Leibniz Centre for Agricultural Landscape Research: Leibniz-Zentrum fur Agrarlandschaftsforschung

Francoise Bringel

Université de Strasbourg: Universite de Strasbourg

Steffen Kolb ( $\boldsymbol{\nabla}$ steffen.kolb@zalf.de)

Leibniz Centre for Agricultural Landscape Research: Leibniz-Zentrum fur Agrarlandschaftsforschung e V https://orcid.org/0000-0002-5455-8662

\section{Research Article}

Keywords: Stable Isotope Probing, Chloromethane, VOCs, methylotrophy

Posted Date: December 28th, 2021

DOI: https://doi.org/10.21203/rs.3.rs-1145955/v1

License: (c) (i) This work is licensed under a Creative Commons Attribution 4.0 International License.

Read Full License 


\section{A Putatively New Family of Alphaproteobacterial Chloromethane Degraders}

2 Microbial Biogeochemistry, RA Landscape Functioning, ZALF Leibniz Centre for Agricultural Landscape Research, Müncheberg, Germany; Saranya.Kanukollu@zalf.de, Sonja.Wende@zalf.de

3 Génétique Moléculaire, Génomique, Microbiologie (GMGM), Université de Strasbourg, UMR 7156 CNRS, 11 Strasbourg, France, francoise.bringel@unistra.fr

4 Thaer Institute, Faculty of Life Sciences, Humboldt University of Berlin, Germany 13

* $\quad$ Correspondence: Steffen.Kolb@zalf.de; Tel.: +49 (0)33432 82-326 15 
$\begin{array}{ll}\text { Abstract } & 50\end{array}$

51

Background:

Chloromethane $\left(\mathrm{CH}_{3} \mathrm{Cl}\right)$ is the most abundant halogenated organic compound in the atmosphere and 53 substantially responsible for the destruction of the stratospheric ozone layer. Since anthropogenic 54 $\mathrm{CH}_{3} \mathrm{Cl}$ sources have become negligible with the application of the Montreal Protocol (1987), natural 55 sources, such as vegetation and soils, have increased proportionally in the global budget. $\mathrm{CH}_{3} \mathrm{Cl}$-de- 56 grading methylotrophs occurring in soils might be an important and overlooked sink. $\quad 57$

Results\&Conclusions:

The objective of our study was to link the biotic $\mathrm{CH}_{3} \mathrm{Cl}$ sink with the identity of active microorganisms and their biochemical pathways for $\mathrm{CH}_{3} \mathrm{Cl}$ degradation in a deciduous forest soil. When tested in laboratory microcosms, biological $\mathrm{CH}_{3} \mathrm{Cl}$ consumption occurred in leaf litter, senescent leaves, and organic and mineral soil horizons. Highest consumption rates, around $2 \mathrm{mmol} \mathrm{CH}_{3} \mathrm{Cl} \mathrm{g}^{-1}$ dry weight $\mathrm{h}^{-1}$, were measured in organic soil and senescent leaves, suggesting that top soil layers are active (micro-)biological $\mathrm{CH}_{3} \mathrm{Cl}$ degradation compartments of forest ecosystems. The DNA of these $\left[{ }^{13} \mathrm{C}\right]-\mathrm{CH}_{3} \mathrm{Cl}$-degrading microbial communities was labelled using stable isotope probing (SIP), and the corresponding taxa and their metabolic pathways studied using high-throughput metagenomics sequencing analysis. $\left[{ }^{13} \mathrm{C}\right]-$ labelled Metagenome-Assembled Genome closely related to the family Beijerinckiaceae may represent a new methylotroph family of Alphaproteobacteria, which is found in metagenome databases of forest soils samples worldwide. Gene markers of the only known pathway for aerobic $\mathrm{CH}_{3} \mathrm{Cl}$ degradation, via the methyltransferase system encoded by the $\mathrm{CH}_{3} \mathrm{Cl}$ utilisation genes $(\mathrm{cmu})$, were undetected in the DNA-SIP metagenome data, suggesting that biological $\mathrm{CH}_{3} \mathrm{Cl}$ sink in this deciduous forest soil operates by a $\mathrm{cmu}$-independent metabolism.

Keywords: Stable Isotope Probing, Chloromethane, VOCs, methylotrophy

\section{Background}

Chloromethane $\left(\mathrm{CH}_{3} \mathrm{Cl}\right)$ is a well-documented halocarbon and one of the most abundant volatile organic compounds in the atmosphere. The global atmospheric concentration of $\mathrm{CH}_{3} \mathrm{Cl}$ is currently 600 ppt and is responsible for $17 \%$ of halogen-dependent ozone depletion in the stratosphere [1, 2]. Abiotic and biotic processes in plants, grassland, soil, salt marshes, and oceans are the key drivers of 82 global chloromethane formation [2-6]. The major $\mathrm{CH}_{3} \mathrm{Cl}$ sinks in the troposphere are photochemical 83 processes involving $\mathrm{OH}$ radicals [1, 7], i.e. currently estimated as $2.8 \mathrm{Tg} \mathrm{yr}^{-1}$ [2]. Furthermore, micro- 84 bial degradation in top soils is a major global sink of the atmospheric trace compound $\mathrm{CH}_{3} \mathrm{Cl}$ [8-10]. $\quad 85$ However, discrepancies in the $\mathrm{CH}_{3} \mathrm{Cl}$ flux estimates (range between 1.5 and 2.5 million $\mathrm{yr}^{-1}$ ) have 86 been observed between known sources and calculated sinks [1]. Thus, the imbalance of the global $\quad 87$ budget of $\mathrm{CH}_{3} \mathrm{Cl}$ is due to underestimated sinks, notably forest soils and their microbial degradation $\quad 88$ activity. 
Biological sink activity within the forest soils may represent a significant $\mathrm{CH}_{3} \mathrm{Cl}$ contribution of as much as $1.0 \mathrm{Tg} \mathrm{yr}^{-1}[2,7]$. Strong evidence of the $\mathrm{CH}_{3} \mathrm{Cl}$ metabolism by soil bacteria, by both oxidation and 91 hydrolysis in earlier investigations suggests that they are the potential sinks of $\mathrm{CH}_{3} \mathrm{Cl}$ [11-13]. Keppler 92 et al. [14] suggested that microbial soil sink could be $1600 \mathrm{Gg} \mathrm{yr}^{-1}$, which might still be considerably 93 underestimated due to the ubiquitous presence of yet unquantified impact of $\mathrm{CH}_{3} \mathrm{Cl}$ degraders in soils 94 [13].

The microorganisms active in terrestrial sink of $\mathrm{CH}_{3} \mathrm{Cl}$ are poorly characterized compared to other at- $\quad 96$ mospheric trace gases such as methane or nitrous oxide. Among methylotrophs, a few are capable of $\quad 97$ utilizing $\mathrm{CH}_{3} \mathrm{Cl}$ as their primary growth substrate [15-17]. $\mathrm{CH}_{3} \mathrm{Cl}$-degrading bacteria were isolated from 98 diverse natural environments [11, 13,18], including representatives from Alpha-, Beta-, and Gammap- 99 roteobacteria, Actinobacteria, and Firmicutes $[15,19]$. Taxonomically diverse $\mathrm{CH}_{3} \mathrm{Cl}$-degrading bacte- $\quad 100$ ria have been isolated from the soil such as alphaproteobacterial genera Aminobacter, Hyphomicro- 101 bium, Methylorubum, Methylocella, Acidicaldus and Bradyrhizobium [13, 20, 21]. The most compre- 102 hensively characterized metabolic pathway of aerobic $\mathrm{CH}_{3} \mathrm{Cl}$ degradation is the $\mathrm{cmu}$ pathway, studied 103 in detail in a model methylotroph, Methylorubrum extroquens (previously Methylobacterium extor- 104 quens) strain $\mathrm{CM} 4$ [22]. Genes $c m u A$ and $c m u B$ encoding methyltransferases essential for $\mathrm{CH}_{3} \mathrm{Cl} \quad 105$ dehalogenation have been detected in various environments, including forest soils [16, 20, 23-25]. 106 However, the absence of a $\mathrm{cmu}$ genes in active $\mathrm{CH}_{3} \mathrm{Cl}$ degraders in metagenomics and labelling stud- $\quad 107$ ies suggests this pathway is not the only $\mathrm{CH}_{3} \mathrm{Cl}$ degradation pathway $[15,17,19]$ and limits $\mathrm{CH}_{3} \mathrm{Cl}-\quad 108$ degrading bacteria detection by overlooking $\mathrm{cmu}$-independent microbial sink in soils. 109 Stable Isotope Probing (SIP) is a powerful method used in microbial ecology in order to identify spe- $\quad 110$ cific functional groups of microorganisms that incorporate distinct (labeled) substrates without know- 111 ing how to cultivate them in standard laboratory conditions. Such a SIP approach enabled the identifi- 112 cation of key bacterial degraders of naturally occurring $\mathrm{CH}_{3} \mathrm{Cl}$ in a temperate German European $\quad 113$ beech forest soil [20] using 16S rRNA gene-targeted metagenomics. The major consumers of $\mathrm{CH}_{3} \mathrm{Cl}-\quad 114$ derived carbon were identified by $16 \mathrm{~S}$ rRNA gene-targeted belonged to the family Beijerinckiaceae of 115 the class of Alphaproteobacteria [23]. However, in these methylotrophic aerobes, the metabolic 116 $\mathrm{CH}_{3} \mathrm{Cl}$-utilization pathway has not been identified. Also, the precise phylogenetic affiliation of these $\quad 117$ Alphaproteobacteria $\mathrm{CH}_{3} \mathrm{Cl}$ degraders remained elusive. Using the same forest soil location where $\quad 118$ these consumers of $\mathrm{CH}_{3} \mathrm{Cl}$-derived carbon have been identified, this study aims to identify genomic $\quad 119$ and metabolic traits of active aerobic microbial $\mathrm{CH}_{3} \mathrm{Cl}$ degraders [20]. A combination of DNA-SIP and $\quad 120$ high-throughput metagenomic sequencing was used to unravel the active $\mathrm{CH}_{3} \mathrm{Cl}$-degrading bacteria $\quad 121$ and to study their methylotrophic metabolism. 122

\section{Methods}


Soil samples and degraded leaf samples were taken from the Steigerwald, Germany, in June $2017 . \quad 128$

Three organic soil samples, three mineral soil samples and three degraded leaf samples were $\quad 129$ extracted, transported to the laboratory on the same day, and stored overnight at $4^{\circ} \mathrm{C}$ before pro- 130 cessing in the following morning. DNA stable isotope labelling (SIP) experiments were set up with $\quad 131$ three biological replicates to determine the most active layers for chloromethane degradation. Fur- 132 thermore, no substrate-added control incubations and control incubations with potassium cyanide 133 $(20 \mathrm{mM})$ were set up to determine intrinsic chloromethane formation and non-microbial chloro- 134 methane dissipation, respectively. 135 Two grams of organic or mineral soil or degraded leaves were incubated in a 125-mL serum vial 136 and flushed with synthetic air (Linde AG, Germany). Microcosms were set up in three biological 137 replicates by adding ${ }^{13} \mathrm{C}-\mathrm{CH}_{3} \mathrm{Cl}$ (Campro Scientific, Germany) or ${ }^{12} \mathrm{C}-\mathrm{CH}_{3} \mathrm{Cl}$ (Linde AG, Germany), $\quad 138$ to a final concentration of $250 \mathrm{mM} \mathrm{g}^{-1} \mathrm{DW}$ (dry weight). In more detail, serum vials were sealed 139 with butyl rubber stoppers, evacuated to a level of 0.01 bar and flushed three times with synthetic 140 air containing $20 \%$ oxygen and $80 \%$ dinitrogen gas (Linde AG, Germany) to a pressure of 1.2 bar. 141 Finally, $\mathrm{CH}_{3} \mathrm{Cl}$ (Linde, Germany) was added using a $100 \mu \mathrm{L}$ gas-tight syringe (Hamilton, Romania). $\quad 142$ Gas samples were taken with gas-tight syringes and stored in 3-mL, pre-evacuated Exetainers 143 (Labco Limited, England) for further analysis by gas chromatography (GC). After complete degra- 144 dation of $\mathrm{CH}_{3} \mathrm{Cl}$, vials were ventilated, evacuated and flushed with synthetic air as before, and 145 again $\mathrm{CH}_{3} \mathrm{Cl}$ was added. Microcosms were monitored for $\mathrm{CH}_{3} \mathrm{Cl}$ depletion at regular intervals until 146 an incorporation of $100 \mu \mathrm{mol}$ carbon per gram sample (soil or degraded leaves) was achieved. 147 Three biological replicated microcosms were then destructively sampled and frozen at $-20{ }^{\circ} \mathrm{C}$ for $\quad 148$ subsequent DNA isolation. 149 150

Gas chromatography

$\mathrm{CH}_{3} \mathrm{Cl}$ was measured in headspace gas volume by injecting $100 \mu \mathrm{L}$ of a headspace gas sample into a ISQTM Quadrupole GC-MS System using a TRACETM Ultra gas chromatograph (Thermo Fisher Sci155 entific, USA) fitted with a $60 \mathrm{~m}, 0.32 \mathrm{~mm}$ GS-GasPro capillary column (Agilent Technologies, California, USA) with helium as the carrier gas (constant column flow rate, $1.5 \mathrm{~mL} \mathrm{~min}^{-1}$ ). Headspace gas samples $(100 \mu \mathrm{L})$ were injected into the column with a temperature ramp from $40^{\circ} \mathrm{C}$ to $200^{\circ} \mathrm{C}\left(15^{\circ} \mathrm{C}\right.$ increase $\mathrm{min}^{-1}$ ). High-throughput measurements were carried out by the MultiPurpose autosampler MPS (Gerstel Inc., USA). Chromatograms were analyzed with the software Openchrome ${ }^{\circledR}$ (Lablicate $\mathrm{GmbH}$, Germany). $\mathrm{CH}_{3} \mathrm{Cl}$ concentrations were calculated by regression analysis based on a six-point calibration with $\mathrm{CH}_{3} \mathrm{Cl}$ standard ranging from 1 to $75 \mathrm{ppm}$. 
DNA extractions from unincubated samples $\left(\mathrm{T}_{0}\right)$ and samples after incubation with $\mathrm{CH}_{3} \mathrm{Cl}$ were carried out using the FastDNA Spin Kit for Soil (MP Bio Science, Derby, UK). ${ }^{13} \mathrm{C}$-labelled heavy DNA was subsequently separated from unlabeled light ${ }^{12} \mathrm{C}$-DNA using a caesium chloride density gradient ultracentrifugation, as described previously [26]. Density formation across 12 fractions (200 $\mu \mathrm{L}$ each) was

To determine the microbial populations in $\mathrm{T}_{0}$ and 'heavy' and 'light' fractions of the $\left[{ }^{13} \mathrm{C}\right]-\mathrm{CH}_{3} \mathrm{Cl}$ incubations and a "Kitome" sample, Terminal Restriction Fragment Length Polymorphism (T-RFLP) was carried out as described previously [27]. Subsequent 16S rRNA amplicon sequencing was performed on an Illumina Miseq platform at LGC Genomics GmbH, Berlin, Germany. Amplicon reads were analysed using the QIIME pipeline, and singletons and chimaeras were removed using USEARCH v7 [28] and UCHIME [29]. OTU binning was carried out against the GreenGenes database [30].

Metagenome sequencing was carried out using DNA from $\left[{ }^{13} \mathrm{C}\right]-\mathrm{CH}_{3} \mathrm{Cl}$-amended microcosms in three biological replicates, together with three replicates of $\left[{ }^{12} \mathrm{C}\right]-\mathrm{CH}_{3} \mathrm{Cl}$-amended microcosms. Library preparation and sequencing were performed at LGC Genomics $\mathrm{GmbH}$, Berlin, Germany.

Reads of Raw Fastq files were trimmed for the presence of Illumina adapter sequences using Cutadapt version 1.2.1 [31]. The reads were further trimmed by Sickle version 1.200 [32] applying a minimum window quality score of 20 . Quality trimmed metagenome reads were then assembled using 188 metaSPAdes v3.11.1 [33] and binned with MyCC version MyCC_2017 [34] using default settings. Estimation of genome completeness and contamination was carried out using the CheckM program [35]. Taxonomic assignment of each bin was carried out by submitting bins to the Rapid Annotation using Subsystem Technology (RAST) annotation pipeline ('Classic RAST' pipeline) [36]. Average Nucleotide/Amino Acid Identity (ANI/AAI) [37] between different genomes was estimated using one-way ANI (best hit) and two-way ANI (reciprocal best hit) based on Goris et al. [38]. In order to infer phylogenetic relatedness whole genome phylogenetic trees were constructed using Composition Vector Tree (CVTree) [39]. Furthermore, Bins were screened for 16S RNA-encoding gene sequences using rnammer version 1.2 [40] with option -S bac and - $\mathrm{m}$ ssu. To search for presence of functional genes involved in $\mathrm{CH}_{3} \mathrm{Cl}$ degradation within the bins, bins were annotated using Prokka (v1.12) [41] and BlastP [42] searches (cutoff $1 \mathrm{e}-30,>70 \%$ identity, manual check of chromosomal region) were carried out against annotated bins (MAGs) using characterized proteins of cmuA. Furthermore, ShortBRED (version 0.9.3) 189 [43] and GraftM (version 0.13.0) [44] were used to identify cmuA in unassembled metagenomic reads, as described previously [17]. To estimate the distribution of MAGs in public available datasets, metagenomics reads from various regions (Supplementary Table S2) were downloaded from sequence read 
[46] was used to exclude regions that also displayed high identity alignments of length $>50$ bp to the

RefSeq database. These ambiguous regions were previously identified by aligning the bin against ncbi's 208

RefSeq database (downloaded 26.08.2021) using blast+ [47] and filtering for pident >=97 (detailed 209

code: https://github.com/SonWende/MAG2metagenome). 210

211

212

Accession numbers for datasets

214

SIP 16S rRNA amplicon sequencing and SIP metagenome read data of the Steigerwald soils and de- 215 graded leaves have been submitted to the National Center for Biotechnology Information (NCBI) under 216 the BioProject number PRJNA742226.

Results and Discussion $\quad 220$

221 degradation in deciduous forest soil samples by stable isotope labelling and probing experiments using 223 leaf litter, degraded (senescent, partially decomposed) leaves, organic and mineral soil. These samples 224 were incubated in triplicates with either $\left[{ }^{13} \mathrm{C}\right]-\mathrm{CH}_{3} \mathrm{Cl}$ or $\left[{ }^{12} \mathrm{C}\right]-\mathrm{CH}_{3} \mathrm{Cl}$ and $\mathrm{CH}_{3} \mathrm{Cl}$ concentrations were mon- 225 itored over 650 hours. 226

227

$\mathrm{CH}_{3} \mathrm{Cl}$ degradation potential is highest in top layers of the forest floor 228

Rapid and steady consumption of $\mathrm{CH}_{3} \mathrm{Cl}$ was observed in all the tested samples of leaf litter, degraded 230 leaves, organic and mineral soils. Degraded leaves and organic soil displayed the highest $\mathrm{CH}_{3} \mathrm{Cl}$ dissi- 231 pation rates around 1.47 and $1.40 \mathrm{mM} \mathrm{CH}_{3} \mathrm{Cl} \mathrm{g}^{-1} \mathrm{DW} \mathrm{h}^{-1}$ in $\left[{ }^{13} \mathrm{C}\right]-\mathrm{CH}_{3} \mathrm{Cl}$ supplemented condition, respec- 232 tively (Supplementary Figure $\mathrm{S} 1 \mathrm{~A}$ ). $\mathrm{CH}_{3} \mathrm{Cl}$ dissipation rates in $\left[{ }^{12} \mathrm{C}\right]-\mathrm{CH}_{3} \mathrm{Cl}$ incubated samples reached 233 2.05 and $2.02 \mathrm{mM} \mathrm{CH}_{3} \mathrm{Cl} \mathrm{g}^{-1} \mathrm{DW} \mathrm{h}^{-1}$ in degraded leaves and leaf litter, respectively (Supplementary 234 Figure S1B). On the other hand, the lowest $\mathrm{CH}_{3} \mathrm{Cl}$ dissipation rates were observed with the mineral soil 235 (Supplementary Figure S1A,B). Furthermore, control incubations with potassium cyanide did not lead 236 to any $\mathrm{CH}_{3} \mathrm{Cl}$ degradation, confirming that the process is biotic. Thus, the top layers of the forest ground 237 (leaf litter, degraded leaves, and organic horizon) are the most active layers for $\mathrm{CH}_{3} \mathrm{Cl}$ degradation in 238 the tested conditions, as previously found in a study of the same deciduous forest sampling site by 239 Chaignaud et al. 2018 [23]. 240 241

Identification of 2 bacterial genome bins exclusively found in $\left[{ }^{13} \mathrm{C}\right]-\mathrm{CH}_{3} \mathrm{Cl}$ treated microcosms ${ }^{243}$ 
In order to gain insights into the active $\mathrm{CH}_{3} \mathrm{Cl}$-degrading community in the forest soil samples, DNA-SIP 245 microcosms using $\left[{ }^{13} \mathrm{C}\right]-\mathrm{CH}_{3} \mathrm{Cl}$ or $\left[{ }^{12} \mathrm{C}\right]-\mathrm{CH}_{3} \mathrm{Cl}$ were combined with high-throughput sequencing of the 246 16S RNA 'heavy' and 'light' fractions and of the metagenomic DNA of $\left[{ }^{13} \mathrm{C}\right]-\mathrm{CH}_{3} \mathrm{Cl}$ and $\left[{ }^{12} \mathrm{C}\right]-\mathrm{CH}_{3} \mathrm{Cl} \quad 247$ fractions. 16S rRNA amplicon sequencing showed e.g., an enrichment of Actinobacteria in the $\left[{ }^{13} \mathrm{C}\right]-248$ $\mathrm{CH}_{3} \mathrm{Cl}$ 'heavy' fractions compared to $\left[{ }^{13} \mathrm{C}\right]-\mathrm{CH}_{3} \mathrm{Cl}$ 'light' fraction (Supplementary Figure S3). 249 Metagenome reads were assembled and assigned into individual bins (Figure 1). This resulted in the 250 assignment of a total of 105 bins, comprising of $14-24$ bins from each 'heavy' fraction $\left(\left[{ }^{13} \mathrm{C}\right]-\mathrm{CH}_{3} \mathrm{Cl}\right.$ and 251 $\left[{ }^{12} \mathrm{C}\right]-\mathrm{CH}_{3} \mathrm{Cl}$ 'heavy' fractions for degraded leaf samples and organic and mineral soil samples). Two 252 taxa of ${ }^{13} \mathrm{C}$-labelled bacterial genome bins did not occur in the ${ }^{12} \mathrm{C}$ control treatments and occurred 253 exclusively in the $\left[{ }^{13} \mathrm{C}\right]-\mathrm{CH}_{3} \mathrm{Cl}$ treatment: i.e. 'Mineral Soil Bin 2' and 'Degraded leaves bin 11' (Figure 254 1). We reconstructed genome fragments (so called metagenome assembled genomes, MAGs) of the 255 $\left[{ }^{13} \mathrm{C}\right]-\mathrm{CH}_{3} \mathrm{Cl}$ 'heavy' samples, and chose 7 MAGs with the highest quality $(>70 \%$ completeness and 256 $<10 \%$ contamination) for further analyses (Supplementary Table S1). Among those, 'Mineral Soil Bin 2' 257 and 'Degraded leaves bin 11' harboured no 16S RNA-encoding genes. Taxa assignment was proposed 258 according to the closest representative found in the RAST database (Supplementary Table S1). The 259 first represented a member of the Alphaproteobacteria (retrieved from mineral soil) and the second 260 represented a member of Acidobacteria (retrieved from the organic layer and degraded leaves). We 261 reconstructed - based on annotations - relevant metabolic pathways of these two MAGs and refined 262 their phylogenetic affiliation. 263 

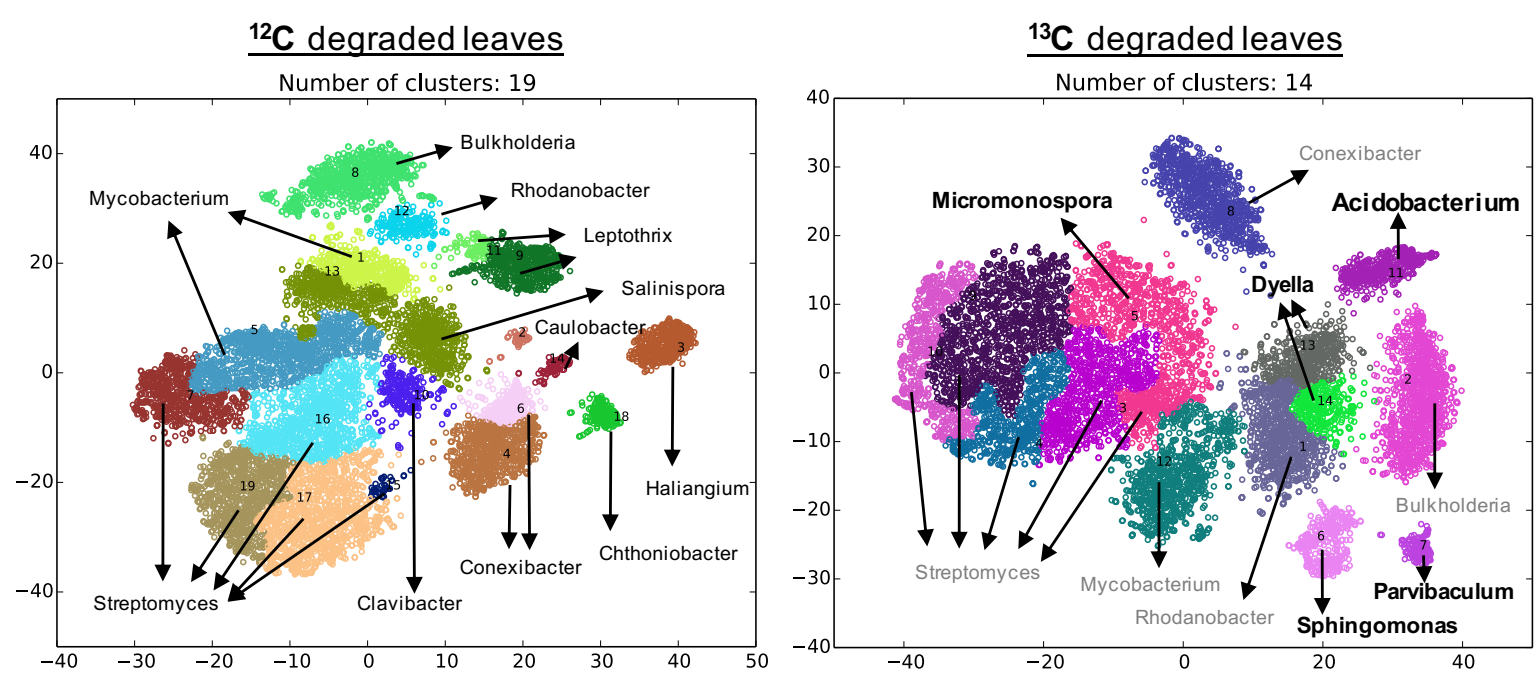

$\underline{{ }^{12} \mathrm{C} \text { organic soil }}$
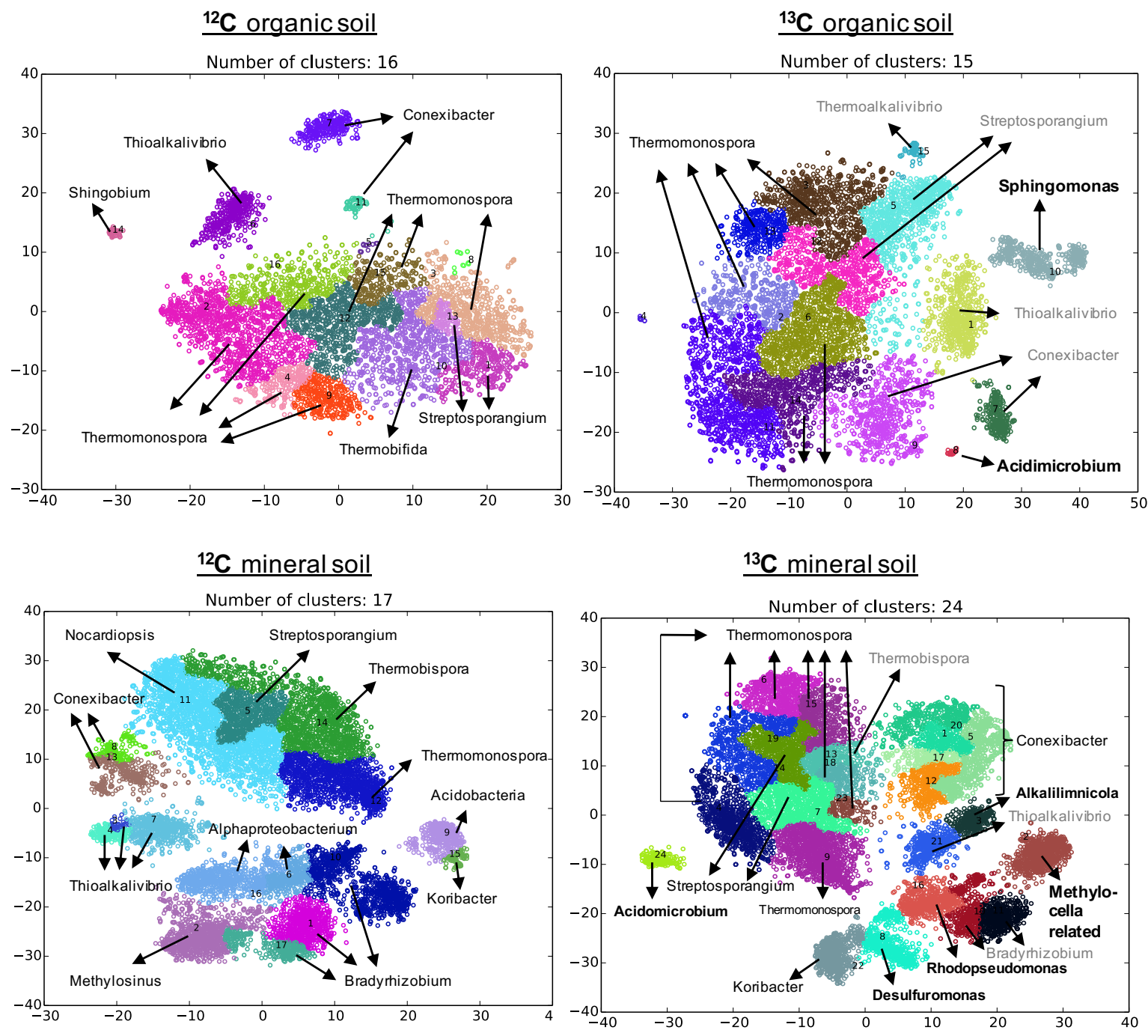

Figure 1. Visual comparison of binned 'heavy' control $\left[{ }^{12} \mathrm{C}\right]-\mathrm{CH}_{3} \mathrm{Cl}$ and labelled $\left[{ }^{13} \mathrm{C}\right]-\mathrm{CH}_{3} \mathrm{Cl}$ incubated met- 272 agenomes from degraded leaves, organic soil and mineral soil. Microbial names that are written in grey 273 in the ${ }^{13} \mathrm{C}-\mathrm{CH}_{3} \mathrm{Cl}$ 'heavy' incubation sample are present in ${ }^{12} \mathrm{C}$ - and ${ }^{13} \mathrm{C}$-'heavy' fractions and are therefore 274 not involved in $\mathrm{CH}_{3} \mathrm{Cl}$ degradation. Microbial names that are written in black are enriched in the ${ }^{13} \mathrm{C}$-'heavy' 275 fraction compared to the ${ }^{12} \mathrm{C}$-'heavy' fraction. Names that are written in bold are microorganisms that are 276 present exclusively in ${ }^{13} \mathrm{C}$-'heavy' fractions and therefore most likely involved in the degradation of $\mathrm{CH}_{3} \mathrm{Cl} \quad 277$ and were used for further analysis. 
The MAG exclusively found in the $\left[{ }^{13} \mathrm{C}\right]-\mathrm{CH}_{3} \mathrm{Cl}$-labelled mineral soil metagenome was related to genomes of Methylocella (Mineral Soil Bin2) (Figure 1). This MAG had a completeness of about $75 \%$ and a contamination of about $4 \%$ (Supplementary Table 1). A phylogenetic tree based on whole genome sequences suggested that this MAG most likely represents a new family closely related to the families Beijerinckiaceae and Methylobacteriaceae within the class of Alphaproteobacteria (Figure 2). We performed comparative genome analyses of average nucleotide identity (ANI) and average amino acid identity (AAI) against closely related genomes from the families Beijerinckiaceae and Methylobacteriaceae, and the data placed this MAG in a novel clade (Figure 2).

The MAG showed $54.4 \%$ AAI to the closely related bacterium Methylocella silvestris and between 52$54 \%$ AAl to genomes of the family Methylobacteriaceae (Figure 2). Therefore, phylogenetic analyses of the whole genome and $\mathrm{ANI}$ analysis both strongly suggest that this unclassified group of $\mathrm{CH}_{3} \mathrm{Cl}-$ enriched bacteria forms a novel family within the class of Alphaproteobacteria. Similarly, in the previous study by Chaignaud et al. [23] on the same deciduous forest soil, microorganisms related to Beijerinckiaceae were also enriched in $\mathrm{CH}_{3} \mathrm{Cl}$-amended stable isotope experiments and only identified on the basis of a partial 16S rRNA sequence so that its phylogenetic positioning remained approximate. To assess the breath of distribution of 'Mineral Soil Bin 2' in the environment, genome mapping was performed by recruiting metagenomic reads from environmental metagenomes using its $\sim 75 \%$ complete genome. Total number of reads that are mapped to 'Mineral Soil Bin 2' can be highly variable (Supplementary Table S2) but detected at high abundance in forest soil samples across the globe (Figure 4). Moreover, reads mapped to the 'Mineral Soil Bin 2' were also detected in soil with different land uses (Figure 4). Highly related OTUs to the closely related Beijerinckia detected by Chaignaud et al. are present in the same forest soil samples across the globe (Supplementary Table S2).

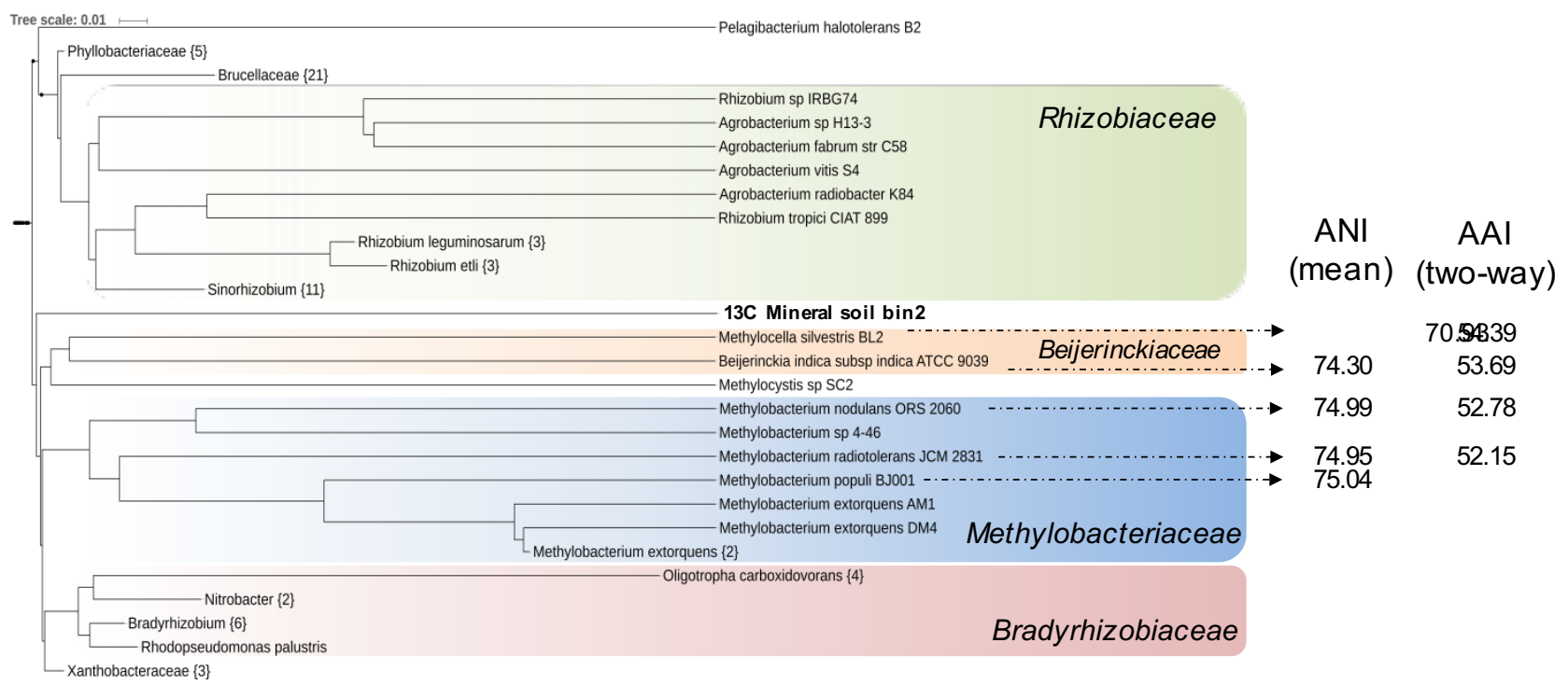


Figure 2. Phylogenetic analysis of whole genome sequences, average nucleotide identity (ANI) and average amino acid identity (AAI) analyses [34] suggest that the MAG "Mineral soil bin 2" is a novel Alphaproteobacterium.

Reconstruction of the metabolic pathways revealed that the 'Mineral soil bin 2' MAG contained two 309 known pathways to oxidize aerobically methyl-groups to carbon dioxide (Figure 3 ) - the tetrahydrofolate 310 $\left(\mathrm{H}_{4} \mathrm{~F}\right)$ and the tetrahydromethaneopterine $\left(\mathrm{H}_{4} \mathrm{MPT}\right)$-dependent formaldehyde oxidation pathways. How311 ever, we could not identify any genes that may code for a dehalogenating enzyme, such as genes 312 cmuAB (assessed by BLAST searches and via ShortBRED and GraftM - data not shown). Also, since 313 Chaignaud et al. could not detect $c m u A$ from Beijerinckiaceae via PCR amplification, the authors sug314 gested that it uses another $\mathrm{CH}_{3} \mathrm{Cl}$ degradation pathway [23]. Despite not having characterized a dehalo315 genating enzyme, the same predominantly ${ }^{13} \mathrm{C}$-labelled taxon may have been labelled in this study and 316 in the previous SIP study by Chaignaud et al. as both studies were conducted with the same forest soil 317 sampling site [23]. Thus, we conclude that this 'Mineral soil bin 2' MAG is most likely responsible for the 318 degradation of the methyl-group $\mathrm{CH}_{3} \mathrm{Cl}$ in these deciduous forest mineral soil samples. Nonetheless, the $\mathrm{CH}_{3} \mathrm{Cl}$ dehalogenating enzyme has yet to be characterized in this taxon.

The $\sim 75 \%$ complete genome sequences retrieved from the $\left[{ }^{13} \mathrm{C}\right]-\mathrm{CH}_{3} \mathrm{Cl}$ DNA SIP-derived MAG provided the opportunity to explore the metabolic potential in this novel bacterium. Figure 3 summarizes its reconstructed metabolic pathways. Complete gene sets for gluconeogenesis, glycolysis and the Entner-Doudoroff pathway were found. Acetyl-phosphate, which is channelled to the central carbon metabolism through acetyl-CoA is converted to generate ATP, and the gene encoding an acetate kinase is also present in the genome. A gene coding for a succinate dehydrogenase is also found. This MAG contains the genes for two known pathways for oxidation of methyl-groups - the $\mathrm{H}_{4} \mathrm{~F}$ and the $\mathrm{H}_{4} \mathrm{MPT}$ dependent pathways, which result in the formation of formate and subsequent carbon dioxide. Genes for the serine cycle or a methane monooxygenase (sMMO/pMMO) were not detected. On the other hand, several alcohol dehydrogenases (EC 1.1.1.1) were found in the MAG. In situ and microcosm studies on forest soils pointed towards soil methylotrophs utilizing $\mathrm{CH}_{3} \mathrm{Cl}$ at low concentration in ppt range that may lead to a limitation of energy conservation needed for bacterial growth [22]. In soils, $\mathrm{CH}_{3} \mathrm{Cl}$ amounts for methylotrophic consumption are much lower than methanol, and key $\mathrm{CH}_{3} \mathrm{Cl}$ degraders use alternative carbon sources such as methanol to subsidize the energy requirements [23]. Many Methylobacteriacea are motile and possess a single polar, subpolar or lateral flagellum [48]. The 'Mineral soil bin 2' MAG does not possess genes encoding for flagellar proteins and is therefore distinct from many members of the closely-related Methylobacteriaceae (Figure 2 and 3). In addition, Methylobacteriaceae normally possess the serine cycle for formaldehyde assimilation [49], which is also absent in 'Mineral soil bin 2' MAG (Figure 3) and hence distinct from these members. Some members of the family Beijerinckiaceae, such as Beijerinckia and Methylocella are diazotrophs [50] with the ability to reduce nitrogen $\left(\mathrm{N}_{2}\right)$ to ammonia $\left(\mathrm{NH}_{3}\right)$ or ammonium $\left(\mathrm{NH}_{4}{ }^{+}\right)$. The closely related 'Mineral soil bin 2' MAG does not possess genes encoding for nitrogen fixation and is therefore distinct from members of Beijerinckia and Methylocella (Figure 2 and 3). These observations strengthen our conclusion that this on $\mathrm{CH}_{3} \mathrm{Cl}$ enriched MAG represents a novel family within the class of Alphaproteobacteria. 


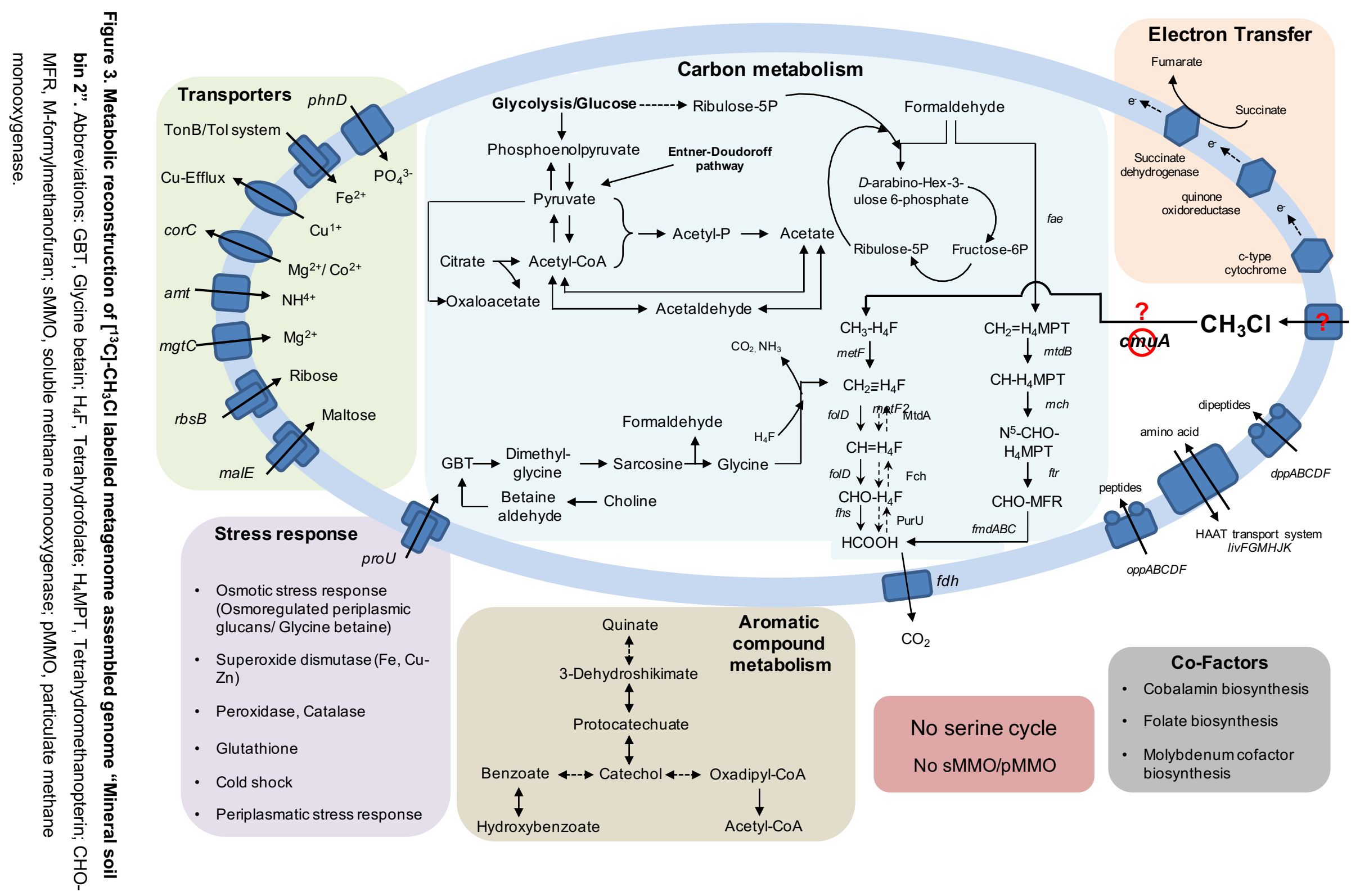


The second MAG 'Senescent Leaves bin 11' was highly similar to genomes of the Acidobacterium 351 Granulicella mallensi, of which members are Gram-negative aerobe rods that have been isolated from 352 soils [51]. The high relatedness of ANI $>87 \%$ suggests that it represents a strain of this species (Sup- 353 plementary Figure S4). Here, a $\mathrm{H}_{4} \mathrm{~F}$-dependent pathway for formaldehyde oxidation was present (Sup- 354 plementary Figure S5). This pathway is well known to function for formaldehyde detoxification. Whether 355 the MAG 'Senescent Leaves bin 11' was labelled by ${ }^{13} \mathrm{C}$-carbon dioxide or even formaldehyde cross- 356 feeding or directly through utilization of $\mathrm{CH}_{3} \mathrm{Cl}$ cannot be excluded. Nonetheless, MAG 'Senescent 357 Leaves bin 11 ' was ${ }^{13} \mathrm{C}$-labelled.

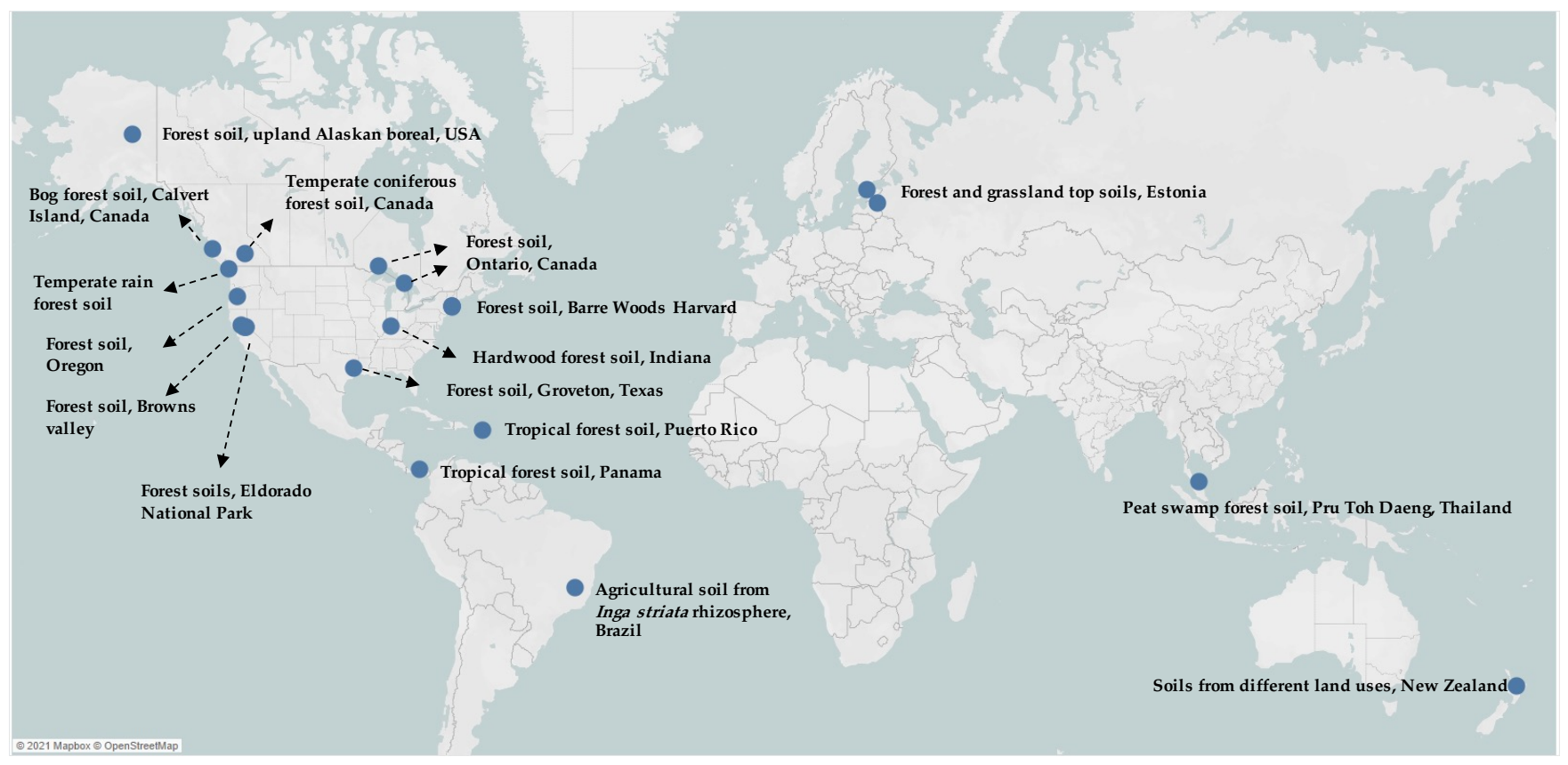

Figure 4. Global distribution of 'Mineral soil bin 2' MAG in forest, grassland and agricultural soil. The map 360 was created with Tableau 2021.3

\section{Conclusions}

Our results suggest that a new key family of aerobic Alphaproteobacteria, 'Mineral soil bin 2' MAG, may be responsible for the degradation of the methyl group of $\mathrm{CH}_{3} \mathrm{Cl}$. However, this organism has not been cultivated and the mechanisms of $\mathrm{CH}_{3} \mathrm{Cl}$ dehalogenation have not been identified. We did not detect cmu genes in the MGA corresponding to this taxon. This may be explained by the $\mathrm{cmu}$ gene plasmid location, as found in $M$. extorquens CM4 [52], which might have thereby escaped metagenome assembly and binning within this MAG. Nonetheless, no cmuA genes were detected in the unassembled metagenomic reads, which strongly suggests an alternative $c m u$-independent mechanism or co-metabolic 
Combining DNA-SIP with metagenomics and assembly allowed the retrieval of a genomes of a puta- 373 tively novel family of Alphaproteobacteria involved in $\mathrm{CH}_{3} \mathrm{Cl}$ degradation in a deciduous forest soil. The 374 results presented in this work demonstrated the power of multi-methodological approaches combining 375 stable isotope labelling and omics to uncover metabolic functions in as-yet uncultivated novel environ- 376 mental microbes. 377 378
377 
Not applicable

Read data of the Steigerwald soil and degraded leave SIP metagenomes have been submitted to the

The authors declare that they have no competing interests.

Funding

This research was funded by the DFG, grant number Ko 2912/10-1.

Authors' contributions

Conceptualization, S.Ko. and E.K.; methodology, E.K.; software, E.K. and S.W.; data analysis and

We acknowledge all partners of the ANR-DFG funded project consortium Chlorofilter (ANR-14-CE350005-01) and Marco Heyde and Ilona Bartelt for assistance during the experiments. 
Supplementary Figure $\mathbf{S 1}: \mathrm{CH}_{3} \mathrm{Cl}$ degradation in deciduous forest soil samples during SIP incubations.

Supplementary Figure S2: Relative distribution of terminal restriction fragments detected by bacterial 447 T-RFLP of fractionated DNA from $\left[{ }^{13} \mathrm{C}\right]-\mathrm{CH}_{3} \mathrm{Cl}$ and $\left[{ }^{12} \mathrm{C}\right]-\mathrm{CH}_{3} \mathrm{Cl}$ SIP incubations of mineral and or- 448 ganic soil samples and degraded leave samples from Steigerwald after incorporation of $100 \mu \mathrm{mol} \quad 449$ $\mathrm{C} \mathrm{g}^{-1}$ sample, $\quad 450$

Supplementary Figure S3: Relative distribution and phylogenetic affiliation of OTUs detected by bacterial 16S rRNA high-throughput amplicon sequencing of samples before SIP experiments (T0) 453 and fractionated DNA from $\left[{ }^{13} \mathrm{C}\right]-\mathrm{CH}_{3} \mathrm{Cl}$ and $\left[{ }^{12} \mathrm{C}\right]-\mathrm{CH}_{3} \mathrm{Cl}$ SIP incubations of mineral and organic soil samples and degraded leave samples from Steigerwald after incorporation of $100 \mu \mathrm{mol} \mathrm{C} \mathrm{g}{ }^{-1}$ sample.

Supplementary Figure S4: Average nucleotide identity (ANI) analysis of "Degraded leaves bin 11" and 458 the closely related Granulicella mallensis and AAl analysis between those two species. 459

Supplementary Figure S5: Metabolic reconstruction of $\left[{ }^{13} \mathrm{C}\right]-\mathrm{CH}_{3} \mathrm{Cl}$ labelled metagenome assembled genome "Degraded leaves bin 11" (closely related to Granulicella mallensis).

Supplementary Table S1: Summary of metagenome-assembled genomes (MAGs) from the $\mathrm{CH}_{3} \mathrm{Cl}-\quad 464$ $\begin{array}{ll}\text { stable isotope probing enrichment. } & 465\end{array}$

Supplementary Table S2: Metagenomes used for read-recruitment against 'Mineral soil bin 2' MAG and the closely related OTU from Chaignaud et al. 2018. 
1. Harper DB. The global chloromethane cycle: biosynthesis, biodegradation and metabolic role. Natural product reports. 2000;17:337-348.

2. Carpenter L, Reimann S, Burkholder J, Clerbaux C, Hall B, Hossaini R, Laube J, Yvon-Lewis S. Scientific assessment of ozone depletion: 2014. World Meteorological Organization Geneva. 2014;10.

3. Yokouchi Y, Takenaka A, Miyazaki Y, Kawamura K, Hiura T. Emission of methyl chloride from a fern growing in subtropical, temperate, and cool-temperate climate zones. Journal of Geophysical Research: Biogeosciences. 2015;120:1142-1149.

4. Rhew RC, Abel T. Measuring simultaneous production and consumption fluxes of methyl chloride and methyl bromide in annual temperate grasslands. Environmental Science \& Technology. 2007;41:7837-7843.

5. Rhew RC, Miller BR, Weiss RF. Natural methyl bromide and methyl chloride emissions from coastal salt marshes. Nature. 2000;403:292-295.

6. Derendorp L, Wishkerman A, Keppler F, McRoberts C, Holzinger R, Röckmann T. Methyl chloride emissions from halophyte leaf litter: Dependence on temperature and chloride content. Chemosphere. 2012;87:483-489.

7. Yoshida Y, Wang Y, Zeng T, Yantosca R. A three-dimensional global model study of atmospheric methyl

8. Harper DB, Hamilton JT. The global cycles of the naturally-occurring monohalomethanes. In Natural Production of Organohalogen Compounds. Springer; 2003: 17-41

9. Keppler F, Harper D, Röckmann T, Moore R, Hamilton J. New insight into the atmospheric chloromethane budget gained using gained using. Atmospheric Chemistry and Physics. 2005;5.

10. Carpenter LJ, Reimann S, Burkholder JB, Clerbaux C, Hall BD, Hossaini R, Laube JC, Yvon-Lewis SA, Engel A, Montzka S. Update on ozone-depleting substances (ODSs) and other gases of interest to the Montreal protocol. Scientific Assessment of Ozone Depletion. 2014:1.1-1.101.

11. Miller LG, Warner KL, Baesman SM, Oremland RS, McDonald IR, Radajewski S, Murrell JC. Degradation of methyl bromide and methyl chloride in soil microcosms: use of stable C isotope fractionation and stable isotope probing to identify reactions and the responsible microorganisms. Geochimica et Cosmochimica Acta. 2004;68:3271-3283.

12. McDonald I, Warner K, McAnulla C, Woodall C, Oremland R, Murrell J. A review of bacterial methyl halide degradation: biochemistry, genetics and molecular ecology. Environmental microbiology. 2002;4:193-203.

13. McAnulla C, McDonald IR, Murrell JC. Methyl chloride utilising bacteria are ubiquitous in the natural environment. FEMS Microbiology Letters. 2001;201:151-155.

14. Keppler F, Harper D, Röckmann T, Moore R, Hamilton J. New insight into the atmospheric chloromethane budget gained using stable carbon isotope ratios. Atmospheric Chemistry and Physics. 2005;5:2403-2411. degrading bacteria by comparative genomics and isotopic fractionation. Frontiers in Microbiology. 2014;5:523.

16. Schäfer H, Miller LG, Oremland RS, Murrell JC. Bacterial cycling of methyl halides. Advances in Applied 522 Microbiology. 2007;61:307-346. 
17. Kröber E, Wende S, Kanukollu S, Buchen-Tschiskale C, Besaury L, Keppler F, Vuilleumier S, Kolb S,

Bringel F. 13C-chloromethane incubations provide evidence for novel bacterial chloromethane degraders in a living tree fern. Environmental Microbiology. 2021.

18. Doronina N, Sokolov A, Trotsenko YA. Isolation and initial characterization of aerobic chloromethaneutilizing bacteria. FEMS Microbiology Letters. 1996;142:179-183.

19. Bringel F, Besaury L, Amato P, Kröber E, Kolb S, Keppler F, Vuilleumier S, Nadalig T. Methylotrophs and 529 methylotroph populations for chloromethane degradation. Current issues in molecular biology. 2019;33:149-172.

20. Coulter C, Hamilton JT, McRoberts WC, Kulakov L, Larkin MJ, Harper DB. Halomethane: bisulfide/halide aerobic methylotroph using chloromethane as the sole carbon source. Applied and Environmental Microbiology. 1999;65:4301-4312.

21. Jaeger N, Besaury L, Kröber E, Delort AM, Greule M, Lenhart K, Nadalig T, Vuilleumier S, Amato P, Kolb

$S$, et al. Chloromethane degradation in soils: A combined microbial and two dimensional stable isotope approach. Journal of Environmental Quality. 2018;47:254-262.

22. Chaignaud P, Maucourt B, Weiman M, Alberti A, Kolb S, Cruveiller S, Vuilleumier S, Bringel F. Genomic and transcriptomic analysis of growth-supporting dehalogenation of chlorinated methanes in Methylobacterium. Frontiers in Microbiology. 2017;8:1600.

23. Chaignaud P, Morawe M, Besaury L, Kröber E, Vuilleumier S, Bringel F, Kolb S. Methanol consumption 542 drives the bacterial chloromethane sink in a forest soil. The ISME journal. 2018;12:2681-2693. 543

24. Borodina E, Cox MJ, McDonald IR, Murrell JC. Use of DNA-stable isotope probing and functional gene 544 probes to investigate the diversity of methyl chloride-utilizing bacteria in soil. Environmental 545 Microbiology. 2005;7:1318-1328.

25. Ul Haque MF, Besaury L, Nadalig T, Bringel F, Mutterer J, Schaller H, Vuilleumier S. Correlated production and consumption of chloromethane in the Arabidopsis thaliana phyllosphere. Scientific reports. 2017;7:1-10.

26. Neufeld JD, Vohra J, Dumont MG, Lueders T, Manefield M, Friedrich MW, Murrell JC. DNA stableisotope probing. Nature Protocols. 2007;2:860-866.

27. Ulrich A, Becker R. Soil parent material is a key determinant of the bacterial community structure in arable soils. FEMS Microbiology Ecology. 2006;56:430-443.

28. Edgar RC. Search and clustering orders of magnitude faster than BLAST. Bioinformatics. 2010;26:24602461.

29. Edgar RC, Haas BJ, Clemente JC, Quince C, Knight R. UCHIME improves sensitivity and speed of chimera detection. Bioinformatics. 2011;27:2194-2200.

30. DeSantis TZ, Hugenholtz P, Larsen N, Rojas M, Brodie EL, Keller K, Huber T, Dalevi D, Hu P, Andersen GL. Greengenes, a chimera-checked 16S rRNA gene database and workbench compatible with ARB. Applied and environmental microbiology. 2006;72:5069-5072.

31. Martin M. Cutadapt removes adapter sequences from high-throughput sequencing reads. EMBnet journal.

32. Joshi N, Fass J: Sickle: a sliding-window, adaptive, quality-based trimming tool for FastQ files. 2011.

33. Nurk S, Meleshko D, Korobeynikov A, Pevzner PA. metaSPAdes: a new versatile metagenomic assembler. Genome research. 2017;27:824-834. 
34. Lin H-H, Liao Y-C. Accurate binning of metagenomic contigs via automated clustering sequences using information of genomic signatures and marker genes. Scientific reports. 2016;6:1-8. 567

35. Parks DH, Imelfort M, Skennerton CT, Hugenholtz P, Tyson GW. CheckM: assessing the quality of 568 microbial genomes recovered from isolates, single cells, and metagenomes. Genome Res. 2015;25:1043- 569 1055.

36. Aziz RK, Bartels D, Best AA, DeJongh M, Disz T, Edwards RA, Formsma K, Gerdes S, Glass EM, Kubal M. The RAST Server: rapid annotations using subsystems technology. BMC Genomics. 2008;9:1-15.

37. Jain C, Rodriguez-R LM, Phillippy AM, Konstantinidis KT, Aluru S. High throughput ANI analysis of 90K prokaryotic genomes reveals clear species boundaries. Nature Communications. 2018;9:5114.

38. Goris J, Konstantinidis KT, Klappenbach JA, Coenye T, Vandamme P, Tiedje JM. DNA-DNA hybridization values and their relationship to whole-genome sequence similarities. International journal of systematic and evolutionary microbiology. 2007;57:81-91.

39. Qi J, Luo H, Hao B. CVTree: a phylogenetic tree reconstruction tool based on whole genomes. Nucleic acids research. 2004;32:W45-W47.

40. Lagesen K, Hallin P, Rødland EA, Stærfeldt H-H, Rognes T, Ussery DW. RNAmmer: consistent and rapid annotation of ribosomal RNA genes. Nucleic acids research. 2007;35:3100-3108.

41. Seemann T. Prokka: rapid prokaryotic genome annotation. Bioinformatics. 2014;30:2068-2069.

42. Altschul SF, Gish W, Miller W, Myers EW, Lipman DJ. Basic local alignment search tool. J Mol Biol. 1990;215:403-410.

43. Kaminski J, Gibson MK, Franzosa EA, Segata N, Dantas G, Huttenhower C. High-specificity targeted functional profiling in microbial communities with ShortBRED. PLoS computational biology. 2015;11:e1004557.

44. Boyd JA, Woodcroft BJ, Tyson GW. GraftM: a tool for scalable, phylogenetically informed classification of genes within metagenomes. Nucleic Acids Research. 2018;46:e59-e59.

45. Bushnell B: BBMap: a fast, accurate, splice-aware aligner. Lawrence Berkeley National Lab.(LBNL), Berkeley, CA (United States); 2014.

46. Quinlan AR, Hall IM. BEDTools: a flexible suite of utilities for comparing genomic features. Bioinformatics. 2010;26:841-842.

47. Camacho C, Coulouris G, Avagyan V, Ma N, Papadopoulos J, Bealer K, Madden TL. BLAST+: architecture and applications. BMC bioinformatics. 2009;10:1-9.

48. McDonald DPKIR, Wood AP. The Family Methylobacteriaceae. 2014.

49. Lidstrom ME. Aerobic methylotrophic prokaryotes. The prokaryotes. 2006;2:618-634.

50. Marin I, Arahal DR. The family Beijerinckiaceae. The prokaryotes. 2014;115:33.

51. Rawat SR, Männistö MK, Starovoytov V, Goodwin L, Nolan M, Hauser LJ, Land M, Davenport KW, Woyke T, Häggblom MM. Complete genome sequence of Granulicella mallensis type strain MP5ACTX8 T, an acidobacterium from tundra soil. Standards in genomic sciences. 2013;9:71-82.

52. Roselli S, Nadalig T, Vuilleumier S, Bringel F. The $380 \mathrm{~kb}$ pCMU01 plasmid encodes chloromethane utilization genes and redundant genes for vitamin B12-and tetrahydrofolate-dependent chloromethane metabolism in Methylobacterium extorquens CM4: a proteomic and bioinformatics study. PLoS One. 2013;8:e56598. 


\section{Supplementary Files}

This is a list of supplementary files associated with this preprint. Click to download.

- SupplFiguresMSSteigerwald.pptx

- SupplementaryTableS2.xlsx 